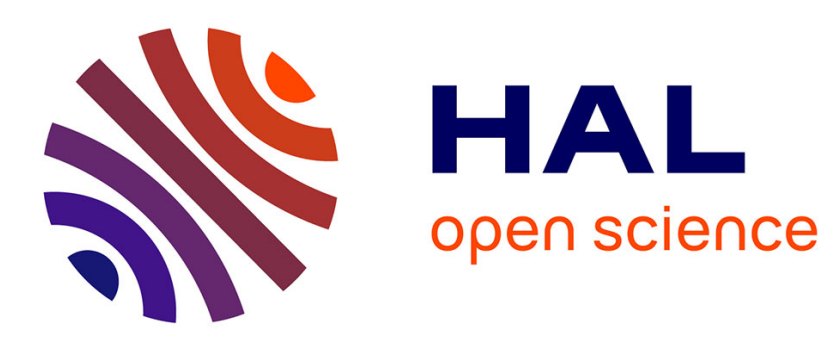

\title{
Martensitic transformation and shape memory effect in B2 intermetallic compounds of titanium
}

\author{
V.N. Khachin
}

\section{To cite this version:}

V.N. Khachin. Martensitic transformation and shape memory effect in B2 intermetallic compounds of titanium. Revue de Physique Appliquée, 1989, 24 (7), pp.733-739. 10.1051/rphysap:01989002407073300 . jpa-00246097

\section{HAL Id: jpa-00246097 https://hal.science/jpa-00246097}

Submitted on 1 Jan 1989

HAL is a multi-disciplinary open access archive for the deposit and dissemination of scientific research documents, whether they are published or not. The documents may come from teaching and research institutions in France or abroad, or from public or private research centers.
L'archive ouverte pluridisciplinaire HAL, est destinée au dépôt et à la diffusion de documents scientifiques de niveau recherche, publiés ou non, émanant des établissements d'enseignement et de recherche français ou étrangers, des laboratoires publics ou privés. 


\title{
Martensitic transformation and shape memory effect in B2 intermetallic compounds of titanium
}

\author{
V. N. Khachin \\ Siberian Physico-Technical Institute, Tomsk State University, Tomsk, U.S.S.R.
}

(Reçu le 16 août 1988, accepté le 28 février 1989)

\begin{abstract}
Résumé. - Nous avons étudié les aspects cristallographiques et cinétiques de la transformation martensitique et les paramètres de l'effet mémoire de forme dans les alliages $\mathrm{Ti}_{50} \mathrm{Ni}_{50-x} \mathrm{X}_{x}(\mathrm{X}=\mathrm{Fe}, \mathrm{Co}, \mathrm{Pd}, \mathrm{Pt}, \mathrm{Au}, \mathrm{Cu})$ et $\mathrm{Ti}_{50} \mathrm{Pd}_{50-x} \mathrm{Y}_{x}(\mathrm{Y}=\mathrm{Fe}, \mathrm{Co}, \mathrm{Cu}), 0 \leqslant x \leqslant 50$. Nous avons mesuré la température, l'hystérésis, la grandeur de la déformation et la contrainte du cisaillement martensitique pour la transformation martensitique et pour l'effet mémoire de forme. Nous avons déterminé les compositions d'alliage donnant des conditions excellentes pour l'effet mémoire de forme.
\end{abstract}

\begin{abstract}
Crystallographic and kinetic characteristics of martensitic transformations and parameters of shape memory effect in $\mathrm{B} 2$ compounds of titanium $\mathrm{Ti}_{50} \mathrm{Ni}_{50-x} \mathrm{X}_{x}(\mathrm{X}=\mathrm{Fe}, \mathrm{Co}, \mathrm{Pd}, \mathrm{Pt}, \mathrm{Au}, \mathrm{Cu})$ and $\mathrm{Ti}_{50} \mathrm{Pd}_{50-x} \mathrm{Y}_{x}(\mathrm{Y}=\mathrm{Fe}, \mathrm{Co}, \mathrm{Cu})$, where $0 \leqslant x \leqslant 50$ are investigated. Temperature, hysteresis, value of reversible deformation and stress of martensitic shear for martensitic transformations and shape memory effect are defined. Compositions of alloys with optimum conditions for shape memory effect were determined.
\end{abstract}

Titanium exists in BCC and HCP modifications $\left(T^{\alpha \rightarrow \beta}=1115 \mathrm{~K}\right)$ and forms binary and multicomponent $\mathrm{B} 2$ compounds with $\mathrm{Ni}, \mathrm{Fe}, \mathrm{Co}, \mathrm{Pd}, \mathrm{Pt}, \mathrm{Au}$, $\mathrm{Cu}$ and other metals, many of them being unstable and undergoing various martensitic transformations (MT) at different temperatures [1-4]. The most famous among them are TiNi and alloys on its base where monoclinic martensitic phase $\mathrm{B}^{\prime} 9^{\prime}$ is formed either directly by B2 $\rightarrow$ B19' or by rhombohedral R structure B2 $\rightarrow R \rightarrow B 19^{\prime}$ [5]. Shape memory effect (SME) is vividly expressed in these alloys. At present new B2 compounds of titanium of the type Ti(Ni, Cu), Ti(Ni, Pd), Ti(Ni, Pt), Ti(Ni, Au), $\mathrm{Ti}(\mathrm{Pd}, \mathrm{Fe})$ with different MT and SME characteristics are intensively investigated $[2-4,6,7]$. Some of the alloys have rare and SME characteristics observed neither in TiNi, nor in other SME alloys. However the results of the researches are not well known. The present paper sums the results of the author's latest publications and presents new data on MT and SME in a series of triple compounds $\mathrm{Ti}_{50} \mathrm{Ni}_{50-x} \mathrm{X}_{x}(\mathrm{X}=\mathrm{Fe}, \mathrm{Co}, \mathrm{Pd}, \mathrm{Pt}, \mathrm{Au}, \mathrm{Cu})$ and $\mathrm{Ti}_{50} \mathrm{Pd}_{50-x} \mathrm{Y}_{x}(\mathrm{Y}=\mathrm{Fe}, \mathrm{Co})$, where $0 \leqslant x \leqslant 50$. The present alloys cover the main compounds of titanium with unstable B2 lattice. The methods of making alloys and specimens as well as methods of structure and SME-studies are described in [2-4].

\section{Martensitic transformations.}

1. SYSTEMS $\mathrm{Ti}_{50} \mathrm{Ni}_{50-x} \mathrm{Fe}_{x}$ AND $\mathrm{Ti}_{50} \mathrm{Ni}_{50-x} \mathrm{Co}_{x}$. MT in $\mathrm{Ti}_{50} \mathrm{Ni}_{50-x} \mathrm{Fe}_{x}(0 \leqslant x \leqslant 3)$ are studied in detail in $[5,8]$. However a total $(0 \leqslant x \leqslant 50)$ MT diagram with cooling up to $4.2 \mathrm{~K}$ is designed only in [9]. At the same time genetically related alloys system $\mathrm{Ti}_{50} \mathrm{Ni}_{50-x} \mathrm{Co}_{x}$ was studied much less. Figure 1 presents the resultant MT diagram which agrees qualitatively with MT diagram in $\mathrm{Ti}_{50} \mathrm{Ni}_{50-x} \mathrm{Fe}_{x}$. In the both systems $\mathrm{B} 2 \rightarrow \mathrm{R} \rightarrow \mathrm{B} 19^{\prime}$ is the basic MT accurately fixed against the temperature dependence of resistivity (Fig. 1a). The parameters of B19' martensitic phase $(a=0.288 \mathrm{~nm}, b=0.412 \mathrm{~nm}$, $c=0.465 \mathrm{~nm}, \quad \beta=97.6^{\circ}$ for $\left.\mathrm{Ti}_{50} \mathrm{Ni}_{4} \mathrm{Co}_{7}\right)$ vary slightly with the change of alloy composition and they are close to the parameters of $\mathrm{B}^{\prime} 9^{\prime}$ martensite in TiNi $(a=0.289 \mathrm{~nm}, b=0.412 \mathrm{~nm}, c=0.464 \mathrm{~nm}$, $\left.\beta=97.3^{\circ}\right)$.

With the increasing of $\mathrm{Co}(\mathrm{Fe})$ content at first MT $R \rightarrow B 19^{\prime}$ and then MT B2 $\rightarrow R$ are under suppression. The stabilization of initial B2 structure in its 


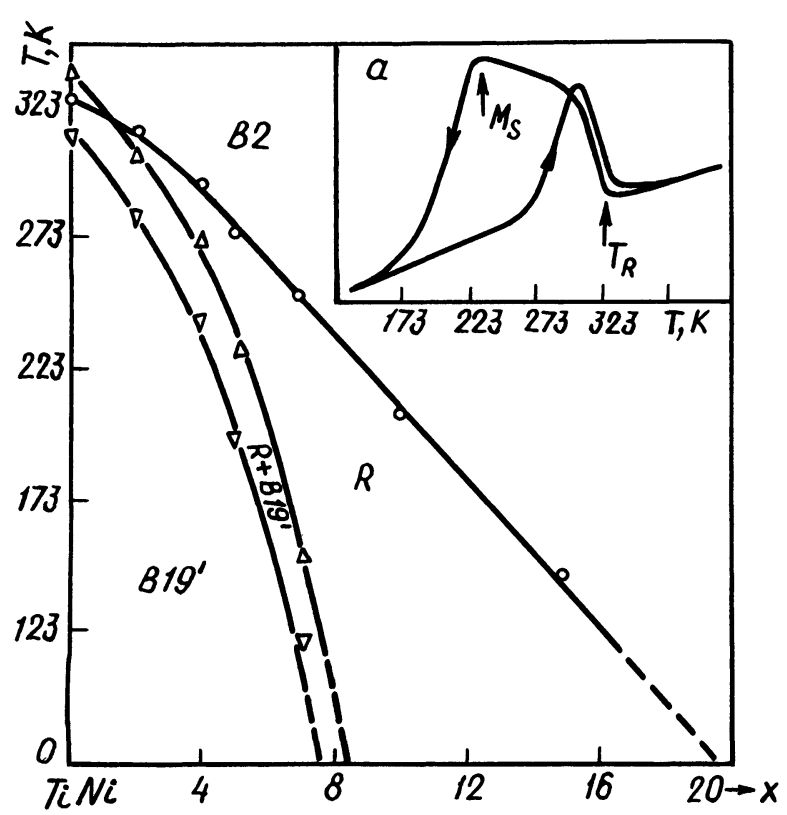

Fig. 1. - Diagram MT of composition $\mathrm{Ti}_{50} \mathrm{Ni}_{50-x} \mathrm{Co}_{x}$ dependences of resistivity $\mathrm{Ti}_{50} \mathrm{Ni}_{45} \mathrm{Co}_{5}$ (a).

transition from TiNi to TiCo (TiFe) is accompanied by a qualitative variation of elastic properties of crystal lattice. It should be stressed here that data on single crystals $\mathrm{Ti}_{50} \mathrm{Ni}_{50-x} \mathrm{Fe}_{x}(0 \leqslant x \leqslant 50)$ obtained in $[10,11]$ are of particular interest. The effect of premartensitic softening of lattice $\left(\mathrm{d} C_{44} / \mathrm{d} T>0\right.$, $\mathrm{d} C^{\prime} / \mathrm{d} T>0, A=C_{44} / C^{\prime} \approx 2$ ) in alloys on $\mathrm{TiNi}$ basis gradually disappears in the process of transition to alloys undergoing no MT therefore the temperature dependence of elastic constants goes to normal $\left(\mathrm{d} C_{44} / \mathrm{d} T<0, \mathrm{~d} C^{\prime} / \mathrm{d} T<0, A<1\right)$.

2. Systems $\mathrm{Ti}_{50} \mathrm{Ni}_{50-x} X_{x}(X=\mathrm{Pd}, \mathrm{Pt}, \mathrm{Au}, \mathrm{Cu})$. For all alloys of these systems MT evolution is the same in quality at increasing $x$. Figure 2 presents the typical MT diagram. Similar diagram was observed in $\mathrm{Ti}_{50} \mathrm{Ni}_{50-x} \mathrm{Pd}_{x}$ [3], $\mathrm{Ti}_{50} \mathrm{Ni}_{50-x} \mathrm{Au}_{x}$ [4] and $\mathrm{Ti}_{50} \mathrm{Ni}_{50-x} \mathrm{Cu}_{x}$ [2]. The characteristic feature of these diagrams is the change of MT B2 $\rightarrow \mathrm{R} \rightarrow \mathrm{B} 19^{\prime}$ $(x<7)$ into B2 $\rightarrow \mathrm{B} 19 \rightarrow \mathrm{B} 19^{\prime}(7<x<14)$ and then into B2 $\rightarrow$ B19 $(x>14)$ sequence, where B19 is orthorhombic phase. B19 and B19' martensitic phases have two different space groups, where B19' is $P 2_{1} / m$ with a distortion of the angle $\beta$ (Fig. 3, curve 1) and $B 19$ is $P 2_{1} / m 2 / m 2 / a$. So the parameters of B19 and B19' martensitic phases undergo significant variations with the change of alloy composition. Figure 3 presents the evolution of parameters B19 and $\mathrm{B}^{\prime} 9^{\prime}$ in $\mathrm{Ti}_{50} \mathrm{Ni}_{50-x} \mathrm{Pt}_{x}$. Similar complete evolution is observed in $\mathrm{Ti}_{50} \mathrm{Ni}_{50-x} \mathrm{Pd}_{x}$ [3], $\mathrm{Ti}_{50} \mathrm{Ni}_{50-x} \mathrm{Au}_{x}$ [4] and close one in $\mathrm{Ti}_{50} \mathrm{Ni}_{50-x} \mathrm{Cu}_{x}$ [2].

The uncommon crystallogeometric peculiarity observed during MT B2 $\rightarrow \mathrm{B} 19 \rightarrow \mathrm{B} 19^{\prime}$ is of great interest. As is seen in figure 3, crystal lattice undergoes no deformation in the direction of parameter $b$

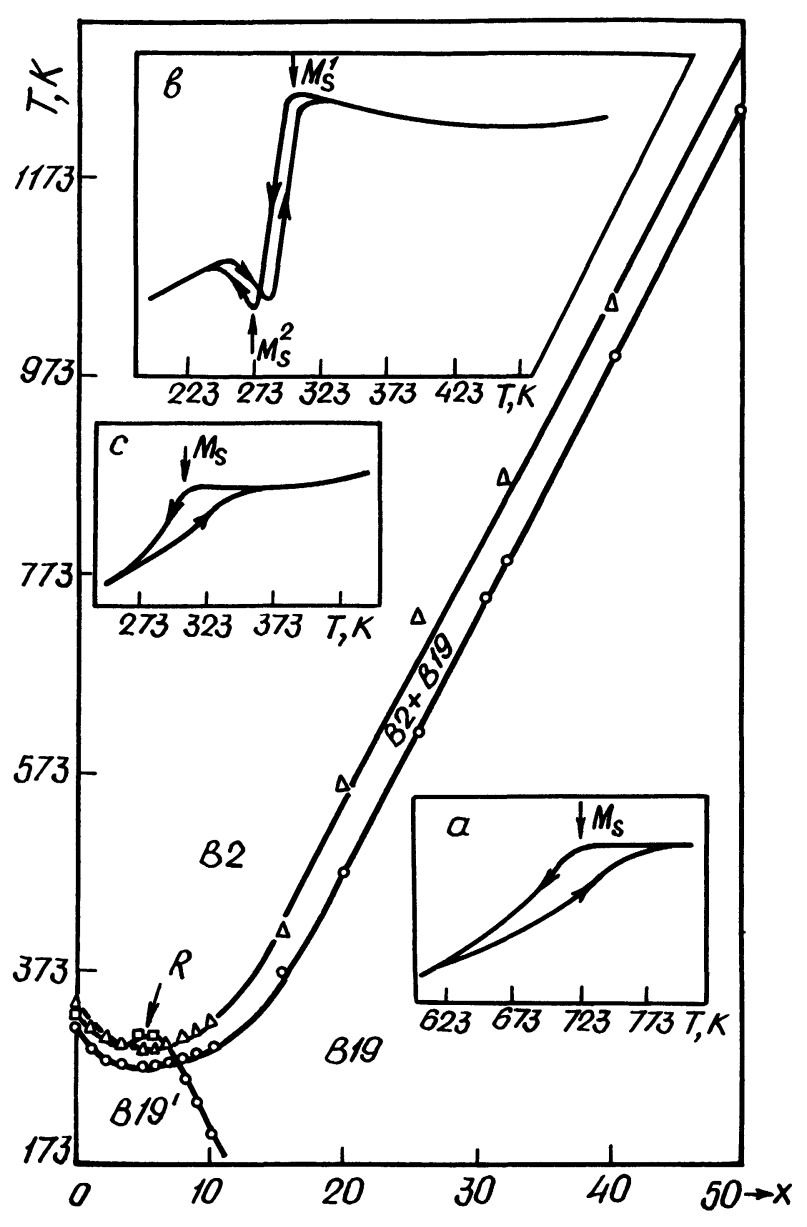

Fig. 2. - Diagram MT of composition $\mathrm{Ti}_{50} \mathrm{Ni}_{50-x} \mathrm{Pt}_{x}$ and temperature dependences of resistivity $\mathrm{Ti}_{50} \mathrm{Ni}_{25} \mathrm{Pt}_{25}$ (a), $\mathrm{Ti}_{50} \mathrm{Ni}_{42.5} \mathrm{Pt}_{7.5}$ (b) and $\mathrm{Ti}_{50} \mathrm{Ni}_{48} \mathrm{Pt}_{2}$ (c).

at both MT. The results of Bain's homogeneous deformation calculations for all MT sequences in $\mathrm{Ti}_{50} \mathrm{Ni}_{50-x} \mathrm{Pd}_{x}$ are given in table I. Analogous results are observed for other three systems of alloys as well. The scheme of calculation with the application of tensor strain is presented in [12]. As is seen from the table I, the value and direction of lattice strain are change essentially after the removing of alloy composition from $\mathrm{TiNi}$ and the change of $\mathrm{MT}$ sequence. The main peculiarity of these changes is as follows: one of eigenvalues of tensor strain in transformed into zero (or near zero) at each out of

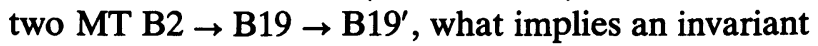
plane to be present. It should be stressed in this connection that the above mentioned plane is the invariant one at microscopic level, that is, it belongs to both crystal lattices simultaneously. Naturally the plane of maximum lattice correspondence is to pass the interface plane (habit plane). In fact, habit plane $\{3 \overline{3} 4\}$ observed experimentally in $\mathrm{Ti}_{50.5} \mathrm{Ni}_{39.5} \mathrm{Cu}_{10}$ [13] is in good agreement with a theoretically calculated $\{19, \overline{19}, 25\}$, which is equivalent to $\{3, \overline{3}, 3.95\}$. The table presents orientation and the 
Table I. - Calculation of lattice strain for martensitic transformations in the $\mathrm{Ti}_{50} \mathrm{Ni}_{50-x} \mathrm{Pd}_{x}$ alloys.

\begin{tabular}{|c|c|c|c|c|c|c|c|c|}
\hline \multirow{2}{*}{$\begin{array}{c}\mathrm{Pd} \text {, } \\
\text { at, \% } \\
1\end{array}$} & \multicolumn{2}{|c|}{$\begin{array}{c}\text { Transformation } \\
\text { type and temperature } \\
\text { of phases parameters } \\
\text { measurements, } K\end{array}$} & $\begin{array}{l}\text { Eigenvalue } \\
\text { of tensor } \\
\text { strain, } \\
\times 10^{2}\end{array}$ & \multicolumn{3}{|c|}{$\begin{array}{l}\text { Coordinates } \\
\text { of } \\
\text { eingenvectors }\end{array}$} & $\begin{array}{c}\text { Symbols } \\
\text { of invariant } \\
\text { plane }\end{array}$ & $\begin{array}{l}\text { Rotation angle of } \\
\text { invariante plane, grad. } \\
\text { The axis of rotation } \\
\text { is }(110) \mathrm{B} 2\end{array}$ \\
\hline & \multicolumn{2}{|c|}{2} & 3 & \multicolumn{3}{|c|}{4} & 5 & 6 \\
\hline \multirow[t]{2}{*}{0} & B2 & B19 & -6.51 & 0.93 & 0 & 0.37 & & \\
\hline & 373 & 293 & $\begin{array}{r}-3.29 \\
11.22\end{array}$ & $\begin{array}{c}0 \\
-0.37\end{array}$ & $\begin{array}{l}1 \\
0\end{array}$ & 0.93 & & \\
\hline \multirow[t]{3}{*}{2} & B2 & B19 & -6.76 & 0.92 & 0 & 0.38 & & \\
\hline & 293 & 273 & -3.16 & 0 & 1 & & & \\
\hline & & & 11.75 & -0.38 & 0 & 0.92 & & \\
\hline \multirow[t]{3}{*}{6} & B2 & B19 & -7.02 & 0.93 & 0 & 0.38 & & \\
\hline & 293 & 293 & -2.64 & & 1 & & & \\
\hline & & & 11.21 & -0.38 & 0 & 0.93 & & \\
\hline \multirow[t]{3}{*}{8.5} & B2 & B19 & -6.31 & 1 & 0 & 0 & $(37 \overline{37} 50)_{\mathrm{B} 2}$ & -3.76 \\
\hline & 273 & 253 & -0.04 & 0 & 1 & 0 & & \\
\hline & & & 6.94 & 0 & 0 & & $(37 \overline{37} \overline{50})_{\mathrm{B} 2}$ & 3.76 \\
\hline \multirow[t]{2}{*}{8.5} & B19 & B19' & -3.91 & 0.64 & 0 & 0.77 & & \\
\hline & 173 & 173 & $\begin{array}{r}-2.26 \\
8.22\end{array}$ & $\begin{array}{c}0 \\
-0.77\end{array}$ & $\begin{array}{l}1 \\
0\end{array}$ & & & \\
\hline \multirow[t]{3}{*}{10} & B2 & B19 & -6.50 & 1 & 0 & 0 & $(17 \overline{17} 25)_{\mathrm{B} 2}$ & -3.84 \\
\hline & 273 & 273 & 0.13 & 0 & 1 & 0 & & \\
\hline & & & 6.90 & $\mathbf{0}$ & 0 & 1 & $(17 \overline{17} \overline{25})_{\mathrm{B} 2}$ & 3.84 \\
\hline \multirow[t]{3}{*}{10} & B19 & B19' & -2.05 & 0.69 & 0 & 0.72 & $(100)_{\mathrm{B} 19}$ & -1.28 \\
\hline & 113 & 113 & 0 & 0 & 1 & 0 & & \\
\hline & & & 2.42 & -0.72 & 0 & 0.69 & $(001)_{\mathrm{B} 19}$ & 1.28 \\
\hline \multirow[t]{2}{*}{25} & B2 & B19 & -9.54 & 1 & 0 & 0 & & \\
\hline & 573 & 293 & $\begin{array}{l}1.86 \\
7.45\end{array}$ & $\begin{array}{l}0 \\
0\end{array}$ & $\begin{array}{l}1 \\
0\end{array}$ & $\begin{array}{l}0 \\
1\end{array}$ & & \\
\hline
\end{tabular}

angle of rotation of habit planes calculated in other alloys which unfortunately have not been observed experimentally as yet.

One more interesting peculiarity of MT $\mathrm{B} 2 \rightarrow \mathrm{B} 19 \rightarrow \mathrm{B} 19^{\prime}$ should be noted here. In the case of the second MT B19 $\rightarrow$ B19' the maximum lattice deformation lies in a plane which was an invariant one at the first transformation. On the contrary, in the case of the first MT B2 $\rightarrow$ B19 the maximum lattice deformation is in the plane which will be invariant one at the second transformation. That is to say, directions of the maximum and zero crystal lattice deformations are interchangeable at the first and second MT. In other words, the formation of complicated monoclinic lattice at MT B2 $\rightarrow$ B19 $\rightarrow$ $\mathrm{B} 19^{\prime}$ is done through two simple «elongation-compression" operations in the two interchangeable directions with the planes undistorted in each case.

One can say that marked crystallographic peculiarities of MT B2 $\rightarrow \mathrm{B} 19 \rightarrow \mathrm{B} 19^{\prime}$ are rare in general not only for MT but also for MT in alloys with SME they are not observed in TiNi. As it will be said later these features will play exceptionally important role in provision of optimum conditions for SME manifestation.

Pay your attention to MT B2 $\rightarrow$ B19 realization at high temperatures with small hysteresis that provides real conditions for high-temperature SME display.

3. SYSTEM $\mathrm{Ti}_{50} \mathrm{Pd}_{50-x} \mathrm{Y}_{x}(\mathrm{Y}=\mathrm{Fe}, \mathrm{Co}, \mathrm{Cu})$. - The compound $\mathrm{Ti}_{50} \mathrm{Pd}_{50}$ undergoes one MT B2 $\rightarrow \mathrm{B} 19$ at $783 \mathrm{~K}[3,14]$. The substitution of palladium for iron or cobalt makes B2 structure stabilized : the temperature of MT B2 $\rightarrow$ B19 falls down (Fig. 4), the effect of premartensitic softening is decreased [15], the lattice strain is suppressed significantly (Fig. 5, curve 1). The present system is suitable for studying distabilization process of $\mathrm{B} 2$ compounds (TiFe and TiCo) with respect to one simple MT B2 $\rightarrow$ B19.

First in the case of alloying TiPd with copper $(<5$ at $\% \mathrm{Cu})$ the temperature of MT B2 $\rightarrow \mathrm{B} 19$ falls down and then with $(>10$ at $\% \mathrm{Cu})$ the 


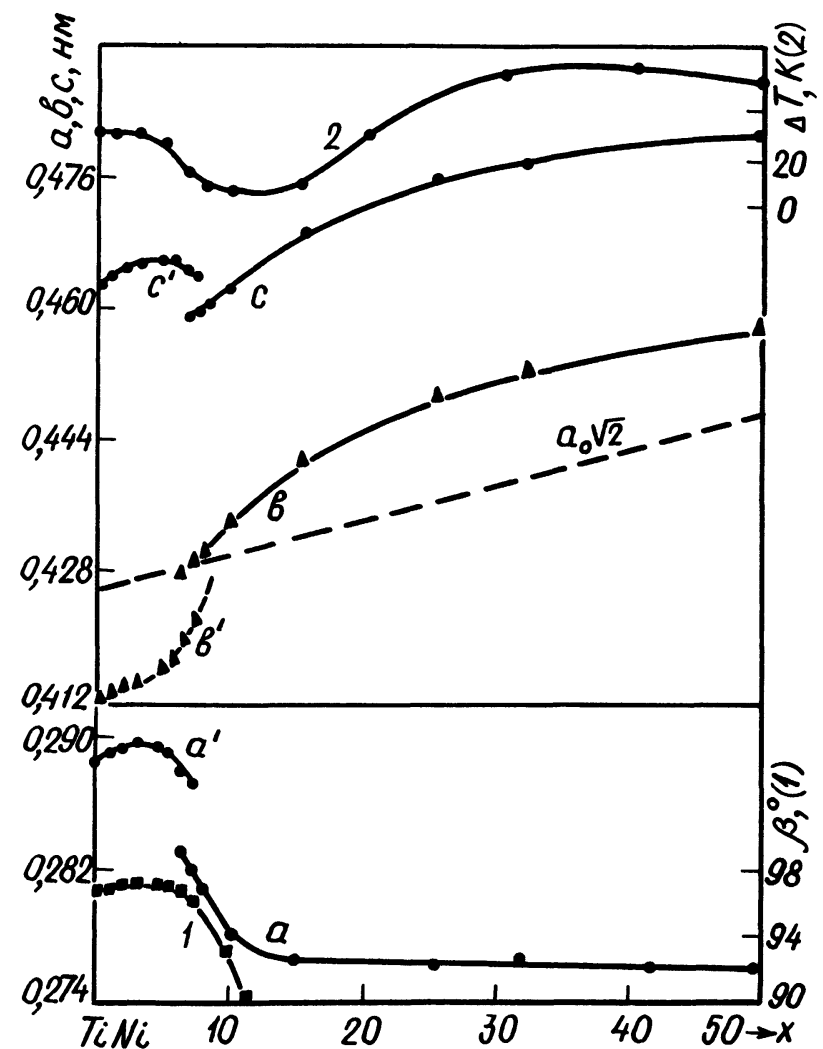

Fig. 3. - The effect of composition of $\mathrm{Ti}(\mathrm{Ni}, \mathrm{Pt})$ on parameters initial $\left(a_{0}\right)$ and martensitic B19 $(a, b, c)$, B19' $\left(a^{\prime}, b^{\prime}, c^{\prime}, \beta\right)$ phases and hysteresis MT.

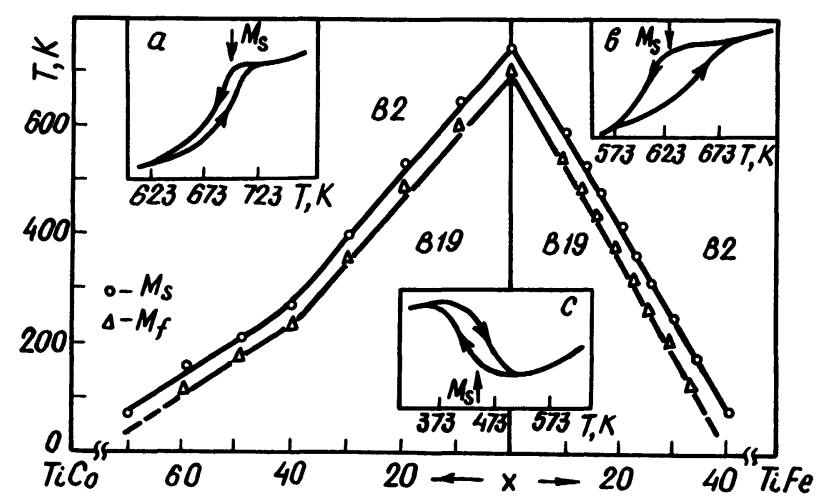

Fig. 4. - Diagram MT of composition $\mathrm{Ti}_{50} \mathrm{Pd}_{50-x} \mathrm{Co}_{x}$ (left) and $\mathrm{Ti}_{50} \mathrm{Pd}_{50-x} \mathrm{Fe}_{x}$ (right) and temperature dependences of resistivity $\mathrm{Ti}_{50} \mathrm{Pd}_{45} \mathrm{Co}_{5}$ (a) and $\mathrm{Ti}_{50} \mathrm{Pd}_{40} \mathrm{Fe}_{10}$ (b), $\mathrm{Ti}_{50} \mathrm{Pd}_{35} \mathrm{Fe}_{15}$ (c).

intensive B2 structure desintegration into two tetragonal phases with the ratio $c / a<1$ and $c / a>1$ occurs. The results of investigations of these alloys will be published separately [16], therefore they are not considered here in detail. In connection with these investigations, work [17] should be noted.

Thus spectrum of MT B2 $\rightarrow \mathrm{B} 19, \mathrm{~B} 2 \rightarrow \mathrm{R}, \mathrm{B} 2 \rightarrow$ $\mathrm{R} \rightarrow \mathrm{B} 19^{\prime}$ and $\mathrm{B} 2 \rightarrow \mathrm{B} 19 \rightarrow \mathrm{B}^{\prime} 9^{\prime}$ are realized in B2 compounds on the basis of titanium. The most

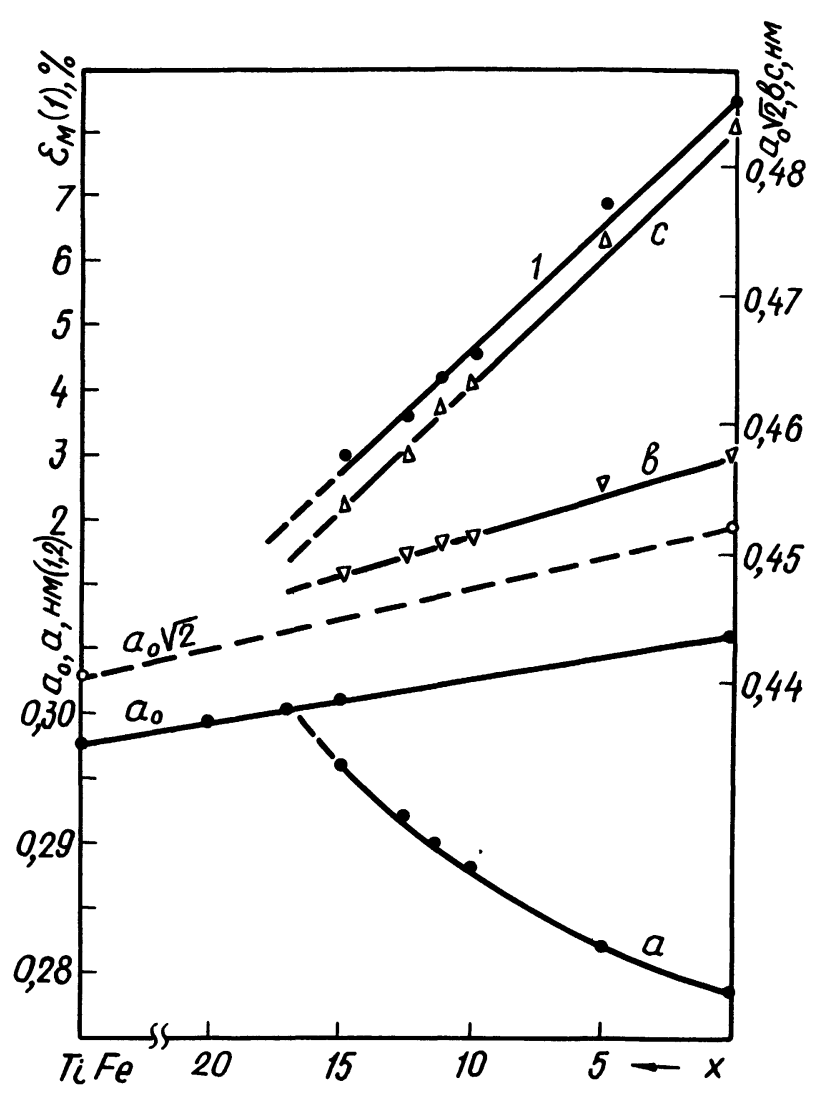

Fig. 5. - The effect of composition of $\mathrm{Ti}(\mathrm{Pd}, \mathrm{Fe})$ on parameters initial $\left(a_{0}\right)$ and martensitic $\mathrm{B} 19(a, b, c)$ phases and value deformation of lattice (1).

interesting cyrstallographic peculiarities are observed at $\mathrm{MT} \mathrm{B} 2 \rightarrow \mathrm{B} 19 \rightarrow \mathrm{B} 19^{\prime}$.

Shape Memory Effect. - Shape memory effect is observed in all alloys during MT with particular temperature, magnitude and hysteresis of reversible strain which are connected with each transformation (Figs. 6, 7).

It should be pointed out that the essential feature of SME at MT B2 $\rightarrow$ B19 is its realization at high temperatures up to $800 \mathrm{~K}$ (Fig. 6, curve 1). However, the magnitude of macroscopic reversible deformation (as a lattice strain - see Tab. I) is relatively not high $-7-8 \%$, but $\sigma_{M}$ is rather high $-150-200$ $\mathrm{MPa}$ even within the interval Ms-Mf. That is, conditions for realizing anelastic (reversible) deformation at MT B2 $\rightarrow R$ are far from optimum ones.

Narrow hysteresis $(3-5 \mathrm{~K})$ and small value $(\sim 1 \%)$ of reversible strain due to closeness of given transformations to transitions of the second order (Fig. 6, curve 2) is the peculiarity of SME at MT B2 $\rightarrow R$. This SME type has been studied well enough earlier, see for example [18].

Undoubtedly, the first and the most evident SME peculiarity at $\mathrm{B} 2 \rightarrow \mathrm{R} \rightarrow \mathrm{B}^{\prime} 9^{\prime}$ and $\mathrm{B} 2 \rightarrow \mathrm{B} 19 \rightarrow \mathrm{B} 19^{\prime}$ is its two-stage character of accumulation and recovery of deformation (Fig. 7), with the resultant revers- 


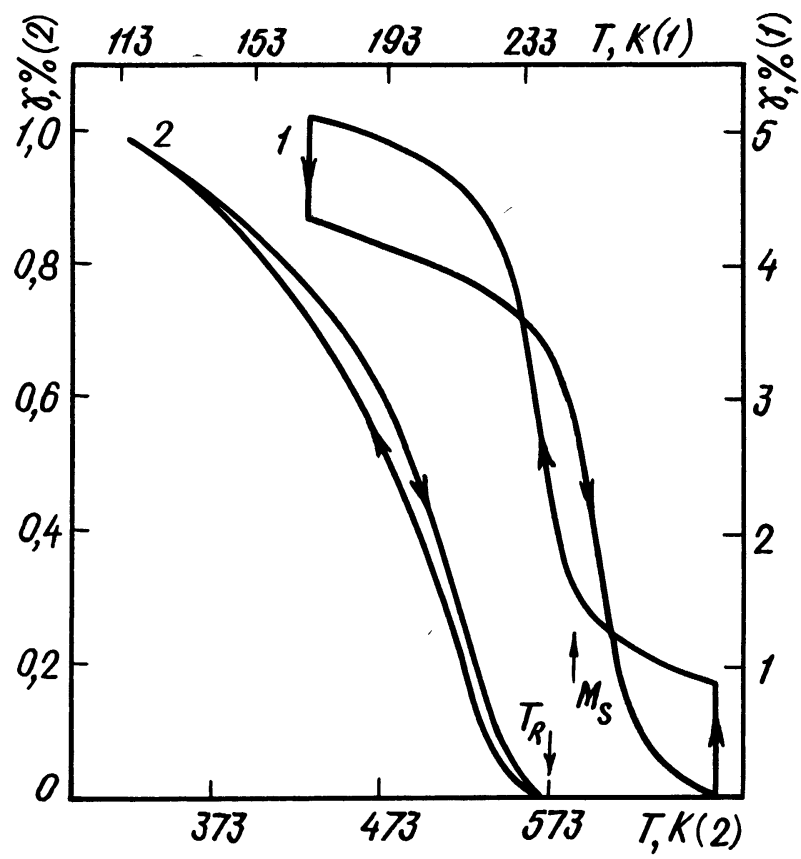

Fig. 6. $-\mathrm{SME}$ at $\mathrm{B} 2 \rightarrow \mathrm{B} 19 \mathrm{MT}$ in $\mathrm{Ti}_{50} \mathrm{Pt}_{36} \mathrm{Ni}_{14}$ (1), and reversible $\mathrm{SME}$ at $\mathrm{B} 2 \rightarrow \mathrm{R} M \mathrm{MT}$ in $\mathrm{Ti}_{50} \mathrm{Ni}_{45} \mathrm{Fe}_{5}$ (2) after prior plastic deformation $7.3 \%$ at $353 \mathrm{~K}$. Stress $200 \mathrm{MPa}$ for (1) suppressed during the heating.

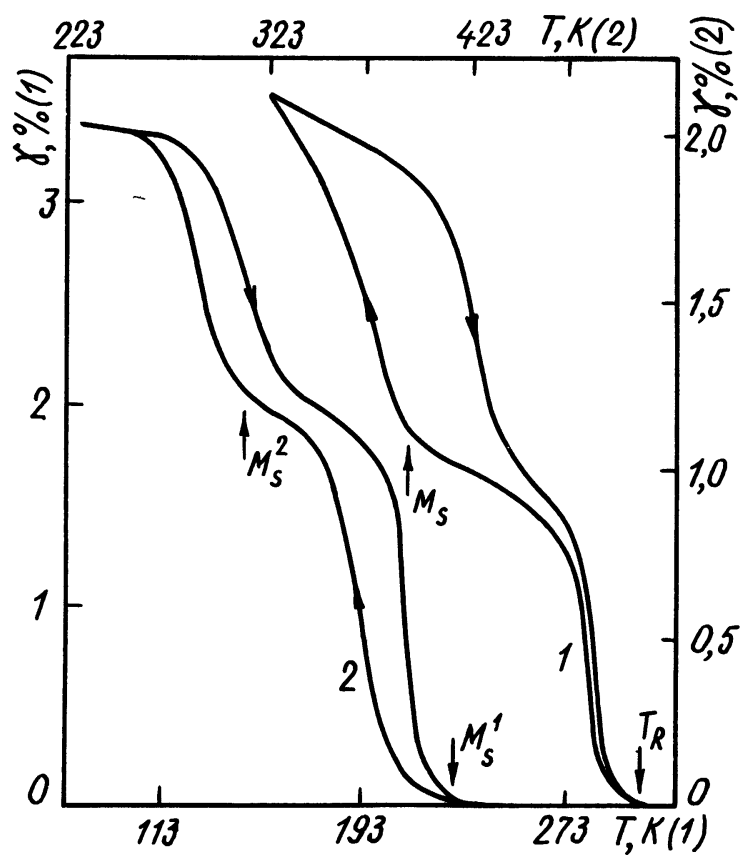

Fig. 7. - Reversible $\mathrm{SME}$ at $\mathrm{B} 2 \rightarrow \mathrm{R} \rightarrow \mathrm{B} 19^{\prime} \mathrm{MT}$ in $\mathrm{Ti}_{49} \mathrm{Ni}_{51}$ (1) and at $\mathrm{B} 2 \rightarrow \mathrm{B} 19 \rightarrow \mathrm{B} 19^{\prime}$ in $\mathrm{Ti}_{50} \mathrm{Ni}_{39} \mathrm{Au}_{11}$ (2) after prior plastic deformatious $6.0 \%$ at $453 \mathrm{~K}$ (1) and $0.3 \%$ at $323 \mathrm{~K}(2)$.

ible strain reaching significant value $-11-12 \%$ [12]. The stress of martensite shear drops sharply. Especially anomalously low values (20-40 MPA) are observed at MT B2 $\rightarrow$ B19 $\rightarrow$ B19' $^{\prime}$ within the interval

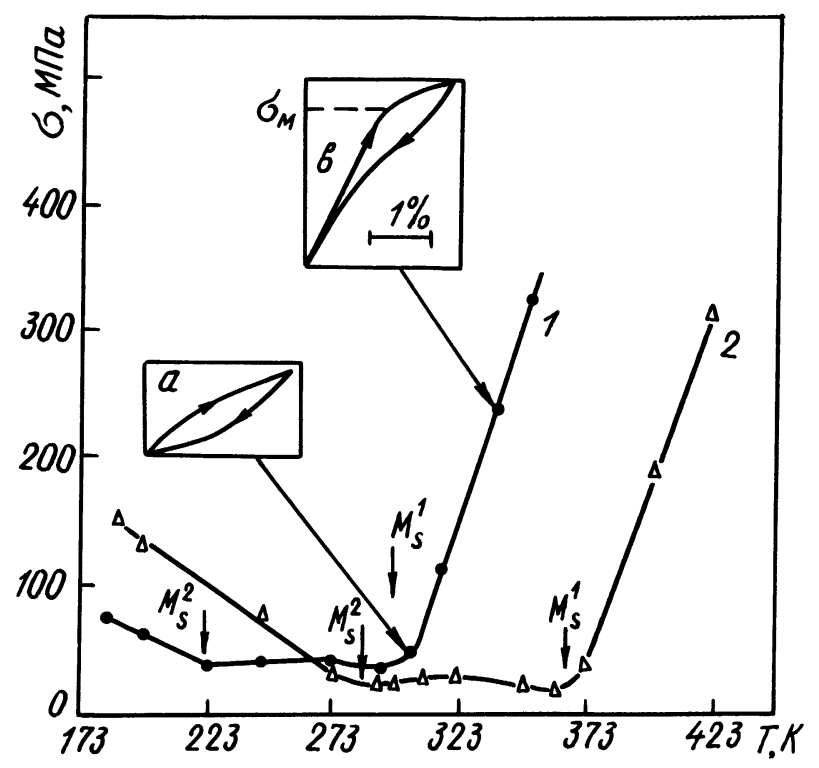

Fig. 8. - Temperature dependence of $\sigma_{M}$ and diagram of $\sigma(\varepsilon)$ in $\mathrm{Ti}_{50} \mathrm{Ni}_{40} \mathrm{Pd}_{10}$ (1) and $\mathrm{Ti}_{50} \mathrm{Ni}_{40} \mathrm{Au}_{10}$ (2).

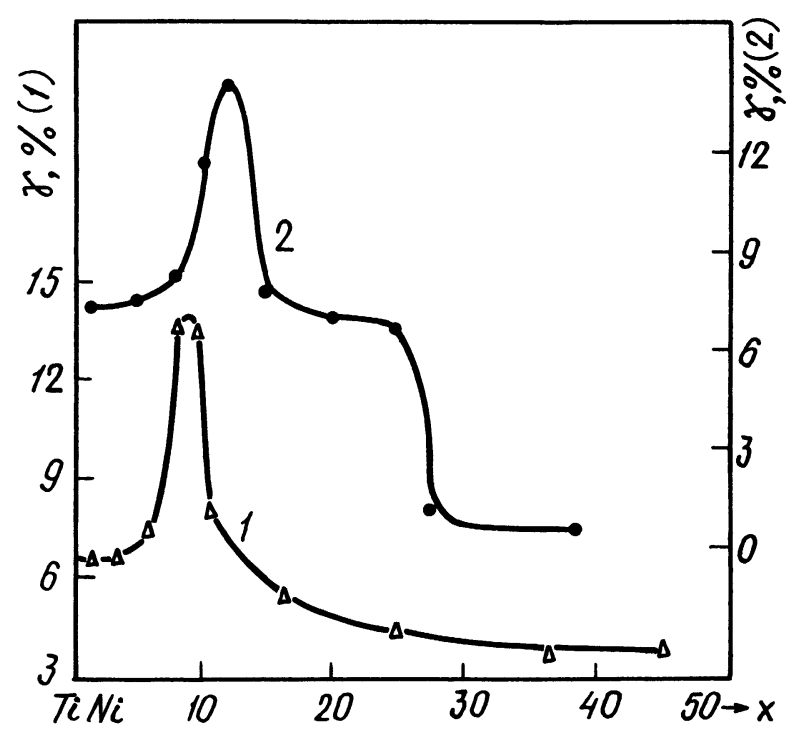

Fig. 9. - The effect of composition of $\mathrm{Ti}(\mathrm{Ni}, \mathrm{Pd})(1)$ and $\mathrm{Ti}(\mathrm{Ni}, \mathrm{Cu})(2)$ on reversible deformation accumulated at cooling alloy with stress $100 \mathrm{MPa}$.

Ms-Mf (Fig. 8). Such MT sequence is characterized by more narrow hysteresis (Fig. 3, curve 2). That is MT B2 $\rightarrow$ B19' is more optimal for SME manifestation what is graphically seen in figure 9 , where the reversible deformation value accumulated under the same stress at the cooling of alloy is at its maximum.

\section{Discussion.}

The MT spectrum is realized in B2 compounds of titanium. Nevertheless only two basic martensitic reactions $\mathrm{B} 2 \rightarrow \mathrm{B} 19$ and $\mathrm{B} 2 \rightarrow \mathrm{R}$ should be chosen 
from the variety of structural transformations and all the rest chains of transformations $\mathrm{B} 2 \rightarrow \mathrm{R} \rightarrow \mathrm{B} 19^{\prime}$ and $\mathrm{B} 2 \rightarrow \mathrm{B} 19 \rightarrow \mathrm{B} 19^{\prime}$ should be regarded as the result of successive realization of these two MT. This is really the case.

As was shown, the formation of MT chains and monoclinic structure of B19' occurs gradually at the change of composition of alloy from TiPd ( $\mathrm{Ti} \mathrm{Pt}$, $\mathrm{TiAu}$ ) to TiNi and further to TiFe (TiCo). So MT $\mathrm{B} 2 \rightarrow \mathrm{B} 19$ are complicated gradually in B2 $\rightarrow \mathrm{B} 19 \rightarrow$ $\mathrm{B} 19^{\prime}$ and through $\mathrm{B} 2 \rightarrow \mathrm{B}^{\prime} 9^{\prime}$ in $\mathrm{B} 2 \rightarrow \mathrm{R} \rightarrow \mathrm{B} 19^{\prime}$. Such MT B2 $\rightarrow$ B19 evolution testifies to gradual destabilization of initial B2 structure to a new MT forming $\mathrm{R}$ phase. The destabilization of $\mathrm{B} 2$ structure occurs gradually and initially $T_{\mathrm{R}}(\mathrm{B} 2 \rightarrow \mathrm{R})$ $M_{\mathrm{S}}(\mathrm{B} 2 \rightarrow \mathrm{B} 19)$. In this case the formation « Rmartensite » in B19 phase gives the results in monoclinic distortion of the latter, that is $\mathrm{B} 19 \rightarrow \mathrm{B} 19^{\prime}$. It is easy to demonstrate it because the direction of [III $]_{\mathrm{B} 2}$ is equivalent to $[\mathrm{IOI}]_{\mathrm{B} 19}$ and rhombohedral deformation of B2 lattice is equivalent to monoclinic B19 distortion relatively. And so, the value of monoclinic distortion depends on intensity of the second (R) MT canal development. Originally, when $T_{\mathrm{R}} \ll M_{\mathrm{S}}$ and « R-canal " starts formation, monoclinic angle is small (Fig. 3, curve 1). As far as the second « R-canal » is developing the temperature of its realization rises and approaches $\left(T_{\mathrm{R}} \approx M_{\mathrm{S}}\right)$ or even exceeds $\left(T_{\mathrm{R}}>M_{\mathrm{S}}\right)$ temperature of the first MT $\left(M_{S}\right)$. The monoclinic angle of B19 structure reaches it maximum and R-phase is formed evidently. It should be pointed out that the monoclinic distortion of B19 phase and the scheme of Bain's deformation are changed simultaneously with the development of the second MT canal. Tension is changed by compression along $b$ axis. Such change is the result of crystallography of MT B19 $\rightarrow$ B19'. The tension of orthohombic lattice along [101] direction, which provides monoclinic distortion should be accompanied by compression of lattice in perpendicular [010] direction which is $b$ axis. In short, both the monoclinic distortion and the compression along $b$ axis are the consequence of only one reason: realization of the second «R-canal» MT.

Thus, the main peculiarities of the MT developing in B2 compounds of titanium can be given as the following scheme

$$
\mathrm{B} 2 \nearrow\left\{\begin{array}{c}
\mathrm{B} 19 \\
+ \\
\mathrm{R}
\end{array}\right\} \rightarrow \mathrm{B} 19^{\prime}
$$

The concrete MT sequence is defined by composition of alloy.

The most striking peculiarity of anelastic behavior of B2 compounds of titanium are anomalously low values of $\sigma_{\mathrm{M}}$ and narrow hysteresis at MT B2 $\rightarrow$ $B 19 \rightarrow B 19$. Such conditions of developing anelastic deformation are associated first of all with crystallogeometry of MT sequence. A total (or near total) lack of the displacements of atoms and internal stress in habit planes $\{334\}_{\mathrm{B} 2}$ (for B2 $\rightarrow$ B19) and $\{100\}$ (for $\mathrm{B} 19 \rightarrow \mathrm{B} 19^{\prime}$ ), that is practically ideal coherence of the interfaces provides a low resistance of material against their motion (low $\sigma_{M}$ and narrow hysteresis).

Low values of elastic modules at the moment MT $[10,11]$ and stage by stage deformation of lattice promotes lowering accomodational strains too and effective development of anelastic deformation. That is to say, the optimum for SME manifestation at $\mathrm{MT}$ B2 $\rightarrow \mathrm{B} 19 \rightarrow \mathrm{B} 19^{\prime}$ is connected with combination of several favourable factors with the presence of total coherence of the interface being determinant among them.

One more peculiarity of anelastic behavior of B2 compounds of titanium is the SME realization at high temperatures in the process of MT B2 $\rightarrow$ B19. It was for the first time that by direct nickel titanium alloying the temperature MT and mechanical properties could be increased simultaneously, this enabled one to preserve thermoelastic property of MT and practically the total SME up to $800 \mathrm{~K}$. It should be noted that SME is not higher than $400-420 \mathrm{~K}$ in alloys on TiNi basis. Naturally, alloy production with high temperature SME broadens the region of its technical application. The scientific value of this result is obvious for the principal possibility of realization of thermoelastic MT SME at higher temperatures than it was believed before. Thus different MT and total SME are realized in B2 compounds of titanium. In this connection B2 compounds of titanium occupy chief position among other alloys with SME and will be a perspective base for the subsequent working out of new alloys of this class.

\section{References}

[1] Savvinov A. S., Sivokha V. P. and Khachin V. N., Metallofizika 5 (1983) 30.

[2] Tokarev V. N., SAVvinov A. S. and KhaChIN V. N., Fiz. Met. i Metalloved. 56 (1983) 340.

[3] Sivokha V. P., Savvinov A. S., Voronin V. P. and Khachin V. N., Fiz. Met. $i$ Metalloved. 56 (1983) 542.
[4] Sivokha V. P. and Khachin V. N., Fiz. Met. $i$ Metalloved. 62 (1986) 534.

[5] Khachin V. N., Paskal Y. I., Gijnter V. E., MANASEVICH L. A. and Sivokha V. P., Fiz. Met. i Metalloved. 46 (1978) 511.

[6] KHACHIN V. N., Izv. VUZov SSSR, Fiz. N5 (1985) 88. 
[7] TADAKI T. and WAYMAN C. M., Metallography 15 (1982) 233, 247.

[8] Wang C. M., Meichle M., Salamon M. B. and Wayman C. M., Philos Mag. A 47 (1983) 9, 31, 177.

[9] ZAKreVski I. G., KoKorin V. V., Muslov S. A., KHACHIN V. N. and SHEVCHENKo A. D., Metallofizika 8 (1986) 91.

[10] Muslov S. A., Khachin V. N., Sivokha V. P. and Pushin V. G., Metallofizika, 9 (1987) 29.

[11] Khachin V. N., Muslov S. A., Pushin V. G. and ChumLikov V. I., Dokl. Akad. Nauk SSSR, 295 (1987) 606.

[12] ZolotukhiN Y. S., SivokHA V. P. and KHACHIN V. N., Fiz. Met. i Metalloved. 66 (1988) 896.
[13] Saburi T., Komatsu T., Nenno S. and Watanabe Y., J. Less-Common. Metals 118 (1986) 217.

[14] Donkersloot H. C. and VAN VuChT Y. M. N., J. Less-Common. Met. 20 (1970) 83.

[15] Voronin V. P. and KHACHIN V. N., Fiz. Met. $i$ Metalloved. 68 (1989).

[16] Voronin V. P. and KHACHIN V. N., Izv. VUZov SSSR, Fiz. (1988) to be published.

[17] EnAmi K., SeKI H. and NenNo S., J. Iron Steel Inst. Jpn 72 (1986) 563.

[18] Khachin V. N., Gijnter V. E., Monasevich L. A. and PASKAL Y. I., Dokl. Akad. Nauk. SSSR 234 (1977) 1059 